\title{
Assessment of Accuracy of Color Doppler in Predicting FGR
}

\author{
Nancy Chakarvarty ${ }^{1}$, Kumkum Srivastav ${ }^{2}$, Sachin Khanduri ${ }^{3}$ \\ ${ }^{1}$ Assistant Professor, Department of Obstetrics and Gynecology, Maharaja Agrasen Medical College, Agroha, Hisar, Haryana, \\ ${ }^{2}$ Professor and Head, Department of Obstetrics and Gynecology, ${ }^{3}$ Professor, Department of Radiodiagnosis, Eras Lucknow \\ Medical College, Lucknow, India
}

Corresponding author: Nancy Chakarvarty, Assistant Professor, Department of Obstetrics and Gynecology, Maharaja Agrasen Medical College, Agroha, Hisar, Haryana, India

DOI: 10.21276/ijcmsr.2018.3.2.12

How to cite this article: Nancy Chakarvarty, Kumkum Srivastav, Sachin Khanduri. Assessment of accuracy of color doppler in predicting FGR. International Journal of Contemporary Medicine Surgery and Radiology. 2018;3(2):B47-B53.

\section{A B S T R A C T}

Introduction: Prediction of risk is the cornerstone of antenatal care. Early prenatal diagnosis of FGR aids in decision making concerning the timing and the route of delivery thereby reducing the perinatal risk. Circulatory changes, reflected in certain fetal Doppler waveforms, predict adverse perinatal outcome. The present work aimed to study the waveforms and color flow of umbilical artery, uterine artery and middle cerebral artery and accuracy of Color Doppler in predicting FGR.

Material and Methods: A total of 100 clinically suspected FGR subjects were enrolled for the purpose of this study Ultrasound examination by Color Doppler carried out serially every three weeks starting from 30 weeks till delivery on Color Doppler machine Chi-square test and Independent Samples t-test was used for statistical analysis. Receiver-Operator curve analysis was performed to find out appropriate cut-off points for prediction of FGR.

Results: For color Doppler, the uterine artery RI was found to be most efficient from the point of view of early detection, it had a sensitivity of $84.6 \%$, specificity of $82.9 \%$ and diagnostic accuracy of $84 \%$ even at 30 week interval. Uterine artery PI was found to be $76.9 \%$ sensitive, $82.9 \%$ specific and had $79 \%$ diagnostic accuracy at 30 weeks. Umbilical artery RI was found to be $80 \%$ sensitive, $74.3 \%$ specific and had a diagnostic accuracy of $78 \%$ at 30 weeks whereas Umbilical artery SD ratio was $70.8 \%$ sensitive and $65.7 \%$ specific and had a diagnostic accuracy of $69 \%$ at 33 weeks interval. MCA RI had only $60 \%$ sensitivity and $71.4 \%$ specificity at 36 weeks interval whereas MCA PI had $66.2 \%$ sensitivity and $68.6 \%$ specificity at 36 weeks interval. MCA PSV was not found to be a useful tool as it did not produce a significant difference between two groups. Conclusion: Doppler measurements for uterine artery showed higher efficacy as compared to umbilical artery and middle cerebral artery findings. Among different umbilical artery measurements, umbilical artery RI was observed to be the most efficient even at early stage (30 weeks). The findings in this study suggested Color Doppler findings have their significance for finding FGR even at the earliest stage (30 weeks).

Key words: Doppler Ultrasound; Fetal Growth; Perinatal Outcome

\section{INTRODUCTION}

Introduction of Doppler ultrasound in medicine has offered a great advantage. The first Doppler ultrasound study of the fetus was reported by Fitzgerald DE, Drumm JE in $1977 .{ }^{1}$ Nowadays, Doppler ultrasound velocimetry of uteroplacental umbilical and fetal vessels has become established method of antenatal monitoring, allowing the noninvasive assessment of fetal circulation. Its indices provide important information on the hemodynamics of the vascular area under study. Circulatory changes, reflected in certain fetal Doppler waveforms, predict adverse perinatal outcome. ${ }^{2}$

Prediction of risk is the cornerstone of antenatal care. Early prenatal diagnosis of FGR aids in decision making concerning the timing and the route of delivery thereby reducing the perinatal risk. Ultrasound evaluation of fetal growth and impedance to blood flow in fetal vessels are the cornerstone for diagnosis, prognosis and management. ${ }^{3}$ The present work aimed to study the waveforms and color flow of umbilical artery, uterine artery and middle cerebral artery and accuracy of Color Doppler in predicting FGR.

\section{MATERIAL AND METHODS}

A total of 100 clinically suspected FGR subjects were enrolled for the purpose of this study from the departments of Obstetrics and Gynecology, Radiology and Pediatrics, Era's Lucknow Medical College and Hospital, Lucknow after informed consent in patient's language. The study was carried over a period of 18 months. This study was approved by Institutional Review Board and Institutional Ethical Committee. Women with singleton pregnancies with fundal height being less than the period of gestation by 4 weeks or more and women with certainty of last menstrual period with previous 3 menstrual cycles (after withdrawal of oral contraceptive pills) were included in the study. Women with Congenital malformations of the fetus were excluded 
from the study. A detailed history and examination was done as per the proforma. Ultrasound examination by Color Doppler carried out serially every three weeks starting from 30 weeks till delivery on Color Doppler machine LOGIQ5-GE machine using $3.5 \mathrm{MHz}$ probe after getting the PNDT forms $\mathrm{F}$ and $\mathrm{G}$ duly explained and signed by the doctor and the patient. Subsequently confirmation of FGR was done by assessing the newborn parameters for growth restriction.

Doppler ulrasound was performed using the macro convex probe (3-5 MHz). $4 \mathrm{MHz}$ ultrasound with pulsed wave Doppler mode and color flow mapping with simultaneous real-time B-mode ultrasound imaging was used to locate and record the umbilical, uterine and middle cerebral artery waveforms.

The recordings were made with an angle of insonation being 30-60 degrees and when at least 4 waves of equal height appeared on the screen. Findings were recorded under Color Doppler as per the designed proforma and tabulated.

\section{STATISTICAL ANALYSIS}

After collection of data the clinical data was correlated with radiological findings using statistical package for social sciences version 15.0. Chi-square test was used to compare the proportions while Independent Samples " $t$ "test was used to compare the parametric variables in two groups. Receiver-Operator curve analysis was performed to find out appropriate cut-off points for prediction of FGR.

\section{RESULTS}

Color Doppler examination involved assessment of blood flow in umbilical, uterine and middle cerebral arteries (table-1).

\begin{tabular}{|c|c|c|c|c|c|c|c|c|c|c|c|}
\hline \multirow[t]{3}{*}{ SN } & \multirow[t]{3}{*}{ Time interval } & \multicolumn{4}{|c|}{ Non-FGR Group ( $n=35)$} & \multicolumn{4}{|c|}{ FGR Group (n=65) } & \multicolumn{2}{|c|}{ Statistical Significance } \\
\hline & & \multirow[t]{2}{*}{ Mean } & \multirow[t]{2}{*}{ SD } & \multicolumn{2}{|c|}{$95 \% \mathrm{Cl}$} & \multirow[t]{2}{*}{ Mean } & \multirow[t]{2}{*}{ SD } & \multicolumn{2}{|c|}{$95 \% \mathrm{Cl}$} & \multirow[t]{2}{*}{ "t" } & \multirow[t]{2}{*}{ "p" } \\
\hline & & & & Lower & Upper & & & Lower & Upper & & \\
\hline 1. & $30 \mathrm{wk}$ & 0.66 & 0.05 & 0.01 & 0.64 & 0.75 & 0.10 & 0.01 & 0.72 & 4.975 & $<0.001$ \\
\hline 2. & 33 wk & 0.69 & 0.11 & 0.02 & 0.65 & 0.81 & 0.18 & 0.02 & 0.76 & 3.616 & $<0.001$ \\
\hline 3. & 36 wk & 0.61 & 0.07 & 0.01 & 0.58 & 0.70 & 0.12 & 0.01 & 0.67 & 4.504 & $<0.001$ \\
\hline 4. & 39 wk & 0.65 & 0.08 & 0.01 & 0.62 & 0.77 & 0.13 & 0.02 & 0.74 & 5.461 & $<0.001$ \\
\hline \multicolumn{2}{|c|}{ Correlation with time } & \multicolumn{4}{|c|}{-0.152} & \multicolumn{4}{|c|}{-0.028} & & \\
\hline
\end{tabular}

\begin{tabular}{|c|c|c|c|c|c|c|c|c|c|c|c|}
\hline \multirow[t]{3}{*}{ SN } & \multirow[t]{3}{*}{ Time interval } & \multicolumn{4}{|c|}{ Non-FGR Group $(n=35)$} & \multicolumn{4}{|c|}{ FGR Group (n=65) } & \multicolumn{2}{|c|}{ Statistical Significance } \\
\hline & & \multirow[t]{2}{*}{ Mean } & \multirow[t]{2}{*}{ SD } & \multicolumn{2}{|c|}{$95 \% \mathrm{Cl}$} & \multirow[t]{2}{*}{ Mean } & \multirow[t]{2}{*}{ SD } & \multicolumn{2}{|c|}{$95 \% \mathrm{Cl}$} & \multirow[t]{2}{*}{ "t" } & \multirow[t]{2}{*}{ "p" } \\
\hline & & & & Lower & Upper & & & Lower & Upper & & \\
\hline 1. & $30 \mathrm{wk}$ & 2.93 & 0.80 & 0.13 & 2.66 & 3.47 & 0.67 & 0.08 & 3.30 & 12.635 & 0.001 \\
\hline 2. & $33 w k$ & 2.75 & 0.73 & 0.12 & 2.50 & 3.48 & 0.78 & 0.10 & 3.29 & 20.744 & $<0.001$ \\
\hline 3. & $36 w k$ & 2.61 & 0.73 & 0.12 & 2.36 & 3.21 & 0.64 & 0.08 & 3.05 & 17.970 & $<0.001$ \\
\hline 4. & $39 w k$ & 2.44 & 0.71 & 0.12 & 2.20 & 3.19 & 0.77 & 0.10 & 3.00 & 22.936 & $<0.001$ \\
\hline \multicolumn{2}{|c|}{ Correlation with time } & \multicolumn{4}{|c|}{-0.208} & \multicolumn{4}{|c|}{-0.163} & & \\
\hline
\end{tabular}

\begin{tabular}{|l|l|c|c|c|c|c|c|c|c|}
\hline \multirow{2}{*}{ SN } & \multirow{2}{*}{ Time interval } & \multicolumn{3}{|c|}{ Non-FGR Group (n=35) } & \multicolumn{3}{c|}{ FGR Group (n=65) } & Statistical Significance \\
\cline { 3 - 10 } & & Mean & SD & $\mathbf{9 5 \% C l}$ & Mean & SD & $\mathbf{9 5 \% C l}$ & "t" & "p" \\
\hline 1. & $30 \mathrm{wk}$ & 0.47 & 0.07 & $0.44-0.49$ & 0.63 & 0.10 & $0.61-0.66$ & 8.438 & $<0.001$ \\
\hline 2. & $33 \mathrm{wk}$ & 0.43 & 0.07 & $0.41-0.46$ & 0.63 & 0.10 & $0.61-0.66$ & 10.272 & $<0.001$ \\
\hline 3. & $36 \mathrm{wk}$ & 0.43 & 0.07 & $0.40-0.45$ & 0.64 & 0.11 & $0.61-0.66$ & 10.714 & $<0.001$ \\
\hline 4. & $39 \mathrm{wk}$ & 0.42 & 0.07 & $0.40-0.45$ & 0.64 & 0.11 & $0.61-0.66$ & 11.041 & $<0.001$ \\
\hline \multicolumn{3}{|c|}{ Correlation with time } & \multicolumn{3}{|c|}{$r=-0.227$} \\
\hline \multicolumn{8}{|c|}{ Table-3: Resistive Index in two groups at different time intervals } & \multicolumn{5}{c|}{ Overall r=-0.026 } \\
\hline
\end{tabular}

\begin{tabular}{|c|c|c|c|c|c|c|c|c|c|c|c|}
\hline \multirow[t]{3}{*}{ SN } & \multirow[t]{3}{*}{ Time interval } & \multicolumn{4}{|c|}{ Non-FGR Group ( $n=35)$} & \multicolumn{4}{|c|}{ FGR Group ( $n=65)$} & \multicolumn{2}{|c|}{ Statistical Significance } \\
\hline & & \multirow[t]{2}{*}{ Mean } & \multirow[t]{2}{*}{ SD } & \multicolumn{2}{|c|}{$95 \% \mathrm{Cl}$} & \multirow[t]{2}{*}{ Mean } & \multirow[t]{2}{*}{ SD } & \multicolumn{2}{|c|}{$95 \% \mathrm{Cl}$} & \multirow[t]{2}{*}{ "t" } & \multirow[t]{2}{*}{ "p" } \\
\hline & & & & Lower & Upper & & & Lower & Upper & & \\
\hline 1. & $30 \mathrm{wk}$ & 46.16 & 11.29 & 1.91 & 42.28 & 47.90 & 8.99 & 1.11 & 45.67 & 0.842 & 0.402 \\
\hline 2. & 33 wk & 48.13 & 12.12 & 2.05 & 43.97 & 49.24 & 9.93 & 1.23 & 46.78 & 0.490 & 0.625 \\
\hline 3. & $36 \mathrm{wk}$ & 51.69 & 13.70 & 2.32 & 46.98 & 55.26 & 13.01 & 1.61 & 52.04 & 1.288 & 0.201 \\
\hline 4. & $39 \mathrm{wk}$ & 60.81 & 16.22 & 2.74 & 55.23 & 60.03 & 15.49 & 1.92 & 56.19 & 0.235 & 0.815 \\
\hline \multicolumn{2}{|c|}{ Correlation with time } & \multicolumn{4}{|c|}{0.360} & \multicolumn{4}{|c|}{0.369} & & \\
\hline
\end{tabular}




\begin{tabular}{|l|l|c|c|c|c|c|c|}
\hline SN & Method & $\begin{array}{c}\text { Gestational } \\
\text { Age (Weeks) }\end{array}$ & Sens & Spec & PPV & $\begin{array}{c}\text { NPV } \\
\text { Diagnostic } \\
\text { Accuracy }\end{array}$ \\
\hline 1. & Uterine artery RI & 30 & 84.6 & 82.9 & 90.2 & 74.4 & 84.0 \\
\hline 2. & Uterine artery PI & 30 & 76.9 & 82.9 & 89.3 & 65.9 & 79.0 \\
\hline 3. & Umbilical artery RI & 30 & 80.0 & 74.3 & 85.2 & 66.7 & 78.0 \\
\hline 4. & Umbilical artery SD Ratio & 33 & 70.8 & 65.7 & 79.3 & 54.8 & 69.0 \\
\hline 5. & MCA RI & 36 & 60.0 & 71.4 & 79.6 & 49.0 & 64.0 \\
\hline 6. & MCA PI & 36 & 66.2 & 68.6 & 79.6 & 52.2 & 67.0 \\
\hline 7. & MCA PSV: Table-5: Diagnostic Efficacy of Color Doppler techniques at different gestational ages \\
\end{tabular}

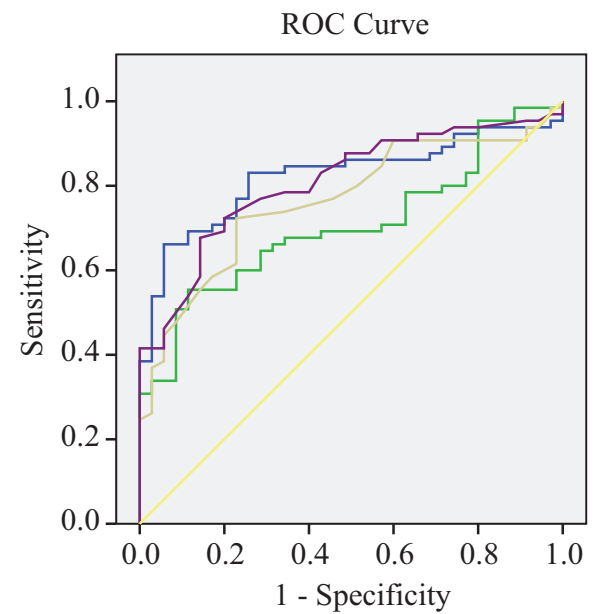

Diagonal segments are produced by ties.

Figure-1: Receiver Operator Curve Analysis to find out appropriate cut-off of Umbilical Artery Resistive Index for FGR detection

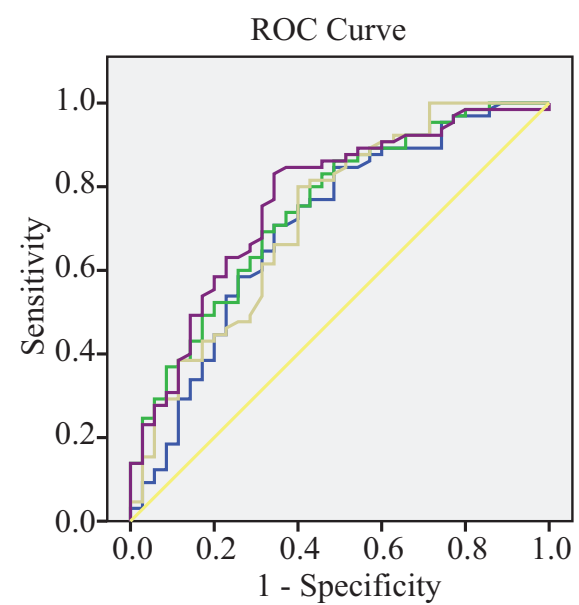

Source of the Curve - SDUMBA30

- SDUMBA33

- SDUMBA36

- SDUMBA39

Reference Line

Diagonal segments are produced by ties.

Figure-2: Receiver Operator Curve Analysis to find out appropriate cut-off of Umbilical Artery SD Ratio for FGR detection

\section{Umbilical Artery}

Statistically significant difference in RI of two groups was seen at all time intervals (table 1 ). The mean $\mathrm{RI}$ in non-FGR group was maximum at 33 weeks $(0.69 \pm 0.11)$ and thereafter it started showed a decline at 36 weeks and finally reached to $0.65 \pm 0.08$ at 39 weeks. In FGR group, the mean RI was maximum at 33 weeks $(0.81 \pm 0.18)$ and minimum at 36 weeks $(0.70 \pm 0.12)$. At 39 weeks, the mean RI in FGR group

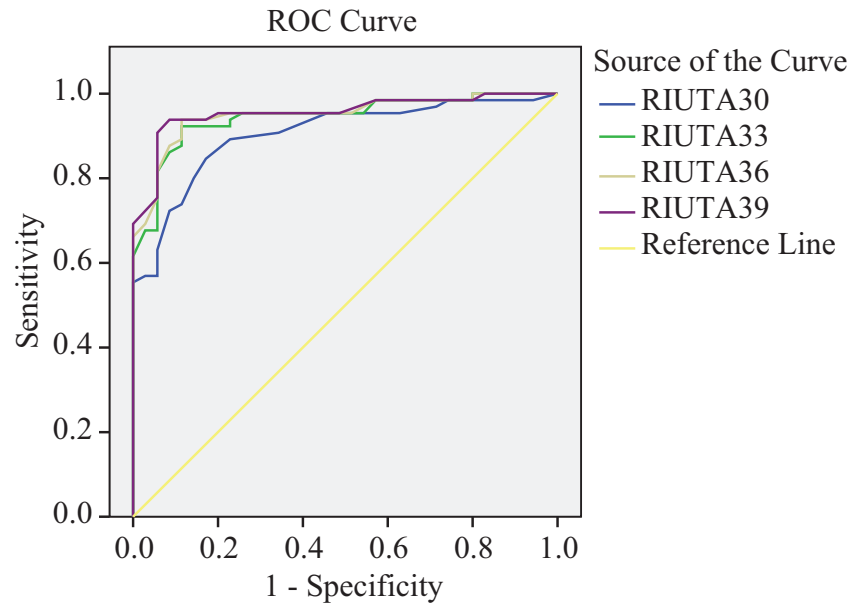

Diagonal segments are produced by ties.

Figure-3: Receiver Operator Curve Analysis to find out appropriate cut-off of RI for FGR detection

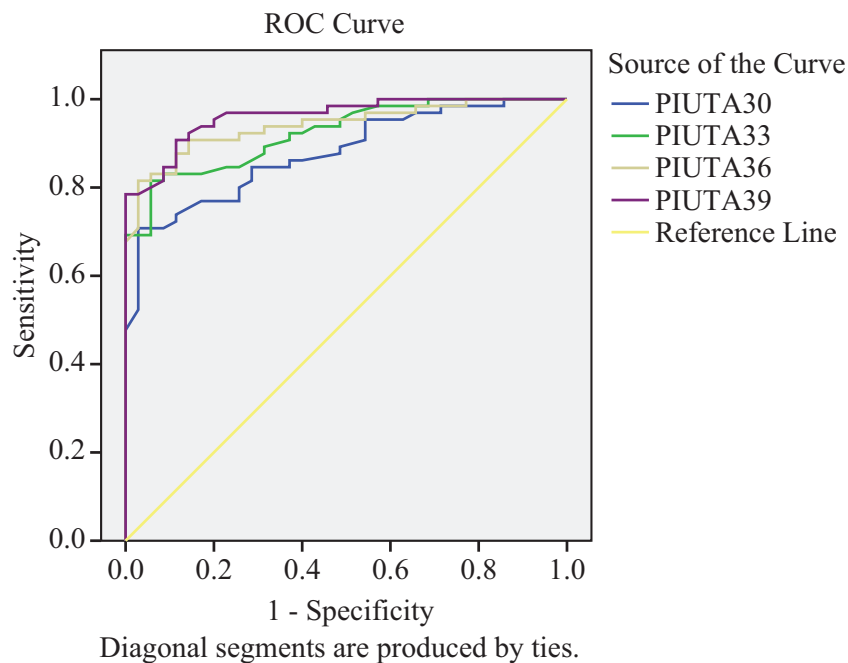

Figure-4: Receiver Operator Curve Analysis to find out appropriate cut-off of uterine artery PI for FGR detection

was $0.77 \pm 0.13$. A very weak to almost negligible inverse correlation between RI and time was observed in both the groups (figure-1).

Umbilical Artery Resistive Index for FGR detection

Receiver operator curve analysis to find out appropriate cutoff of Umbilical Artery Resistive Index for FGR detection (figure 1) showed maximum area under curve at 30 weeks (0.822) while minimum area under curve was seen at 33 weeks. At 30 week the cut-off value of 0.68 was predicted to 


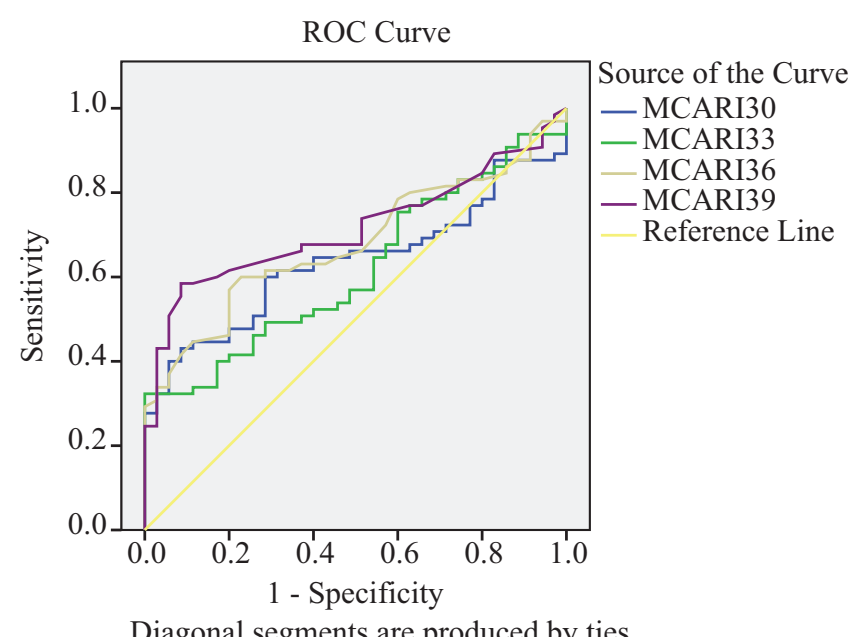

Figure-5: Receiver Operator Curve Analysis to find out appropriate cut-off of MCA RI for FGR detection

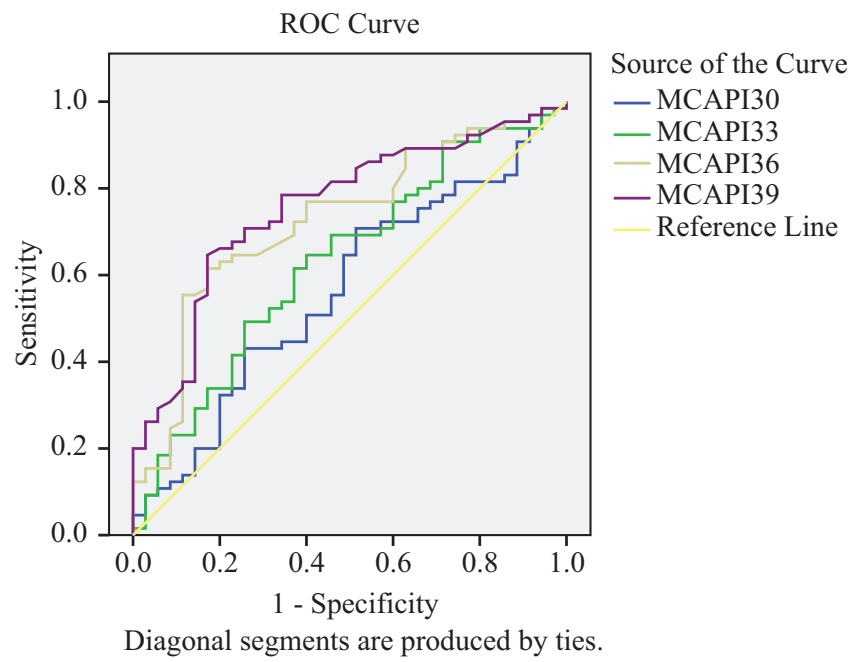

Figure-6: Receiver Operator Curve Analysis to find out appropriate cut-off of MCA PI for FGR detection

be $83.1 \%$ sensitive and $74.3 \%$ specific. Considering the early detectability and maximum accuracy, the 30 weeks cut-off was evaluated for diagnostic accuracy.

Table 2 shows umbilical artery SD ratio in two groups at different time intervals. Statistically significant difference in $\mathrm{SD}$ ratio of two groups was seen at all time intervals. The mean SD ratio in non-FGR group was maximum at 30 weeks $(2.93 \pm 0.80)$ and thereafter it showed a decline to finally reach to $2.44 \pm 0.71$ at 39 weeks. In FGR group, the mean $\mathrm{SD}$ ratio was maximum at 36 weeks $(3.48 \pm 0.78)$ and minimum at 39 weeks $(3.19 \pm 0.77)$. A very weak to almost negligible inverse correlation between SD ratio and time was observed in both the groups.

Receiver operator curve analysis to find out appropriate cutoff of Umbilical Artery SD Ratio for FGR detection (figure 2) showed maximum area under curve at 39 weeks (0.767) while minimum area under curve was seen at 30 weeks (0.706). At 33 weeks the cut-off value of 3.13 was predicted to be $70.8 \%$ sensitive and $65.7 \%$ specific.

Considering the early detectability, the 33 weeks cut-off was evaluated for diagnostic accuracy.

\section{Uterine Artery}

Mean resistive index in uterine artery amongst non-FGR group was found to be significantly lower as compared to FGR group at all gestational ages (table 3). In non-FGR group with the progression of labor, the RI was found to be decreasing mildly ( $\mathrm{r}=-0.227)$ whereas in FGR group correlation with gestational age was almost negligible $(\mathrm{r}=0.033)$. In non-FGR group, minimum mean value was seen at 39 weeks $(0.42 \pm 0.07 ; 95 \%$ CI $0.40-0.45)$ and maximum value was observed at $30 \mathrm{wks}(0.47 \pm 0.07 ; 95 \%$ CI $0.44-0.49)$ while in FGR group minimum value was observed at 30 and 33 weeks $(0.63 \pm 0.10 ; 95 \%$ CI $0.61-0.66)$ while maximum value was observed at 36 and 39 weeks $(0.64 \pm 0.11 ; 95 \%$ CI 0.61-0.66).

Calculation of cut-off with the help of receiver-operator curve (ROC) analysis at different gestational ages is shown in figure 3.

Area under curve was maximum at 39 weeks (0.956) and minimum at 30 weeks (0.904). At 30 weeks the regressed value of $>0.54$ had $84.6 \%$ sensitivity and $82.9 \%$ specificity. At 33 weeks the cut-off value of $>0.535$ had $86.2 \%$ sensitivity and $91.4 \%$ specificity. At 36 weeks too the cut-off value of $>0.535$ had $86.2 \%$ sensitivity and $91.4 \%$ specificity. At 39 weeks the cut-off value of $>0.525$ had $90.8 \%$ sensitivity and $94.3 \%$ specificity.

As the cut-off values at different time intervals had adequate sensitivity and specificity, the value that can differentiate earliest i.e. at 30 weeks time interval was tested for diagnostic efficacy in current series.

Receiver operator curve analysis showed maximum area under curve at 39 weeks (0.962) while minimum area under curve was seen at 30 weeks (figure 4). At 30 weeks the cut-off value of 1.03 was predicted to be $76.9 \%$ sensitive and $82.9 \%$ specific. At 33 wk the cut-off value of 0.905 was regressed to be $83.1 \%$ sensitive and $91.4 \%$ specific. At 36 weeks the cut-off value of 0.96 was regressed to be $83.1 \%$ sensitive and $94.3 \%$ specific. The 39 weeks cut off value of 0.925 was found to be $84.6 \%$ sensitive and $91.4 \%$ specific.

Considering the early detectability and adequate accuracy, the 30 weeks cut-off was evaluated for diagnostic accuracy.

\section{Middle Cerebral Artery}

Statistically significant difference in Middle Cerebral Artery Resistive Index in two groups was seen at all time intervals (table 3). The mean RI in non-FGR group was maximum at 33 weeks $(0.91 \pm 0.15)$ and thereafter it showed a decline to finally reach to $0.83 \pm 0.10$ at 39 weeks. In FGR group, the mean RI was maximum at 33 weeks $(1.04 \pm 0.30)$ and minimum at 36 weeks $(0.95 \pm 0.26)$. A very weak to almost negligible inverse correlation between RI and time was observed in both the groups.

Receiver operator curve analysis showed maximum area under curve at 39 weeks $(0.716)$ while minimum area under curve was seen at 30 weeks (0.646) (figure 5). At 36 weeks the cut-off value of 0.86 was predicted to be $61.6 \%$ sensitive and $71.4 \%$ specific.

The 36 weeks cut-off was evaluated further for diagnostic 
accuracy.

Receiver operator curve analysis showed maximum area under curve at 39 weeks $(0.757)$ while minimum area under curve was seen at 30 weeks (0.565) (figure 6). At 36 weeks the cut-off value of 1.88 was predicted to be $67.7 \%$ sensitive and $65.7 \%$ specific. The 36 weeks cut-off was evaluated further for diagnostic accuracy.

No statistically significant difference between two groups was observed as regards PSV at different time intervals (table 4). The mean PSV in both the groups was minimum at 30 weeks and maximum at 39 weeks. In both the groups a mild positive correlation between time and PSV was observed. As no significant differences were observed between two groups at different time intervals, hence they were not further explored.

Table 5 shows diagnostic efficacy of color doppler techniques at different gestational ages. The uterine artery RI was found to be most efficient from the point of view of early detection, it had a sensitivity of $84.6 \%$, specificity of $82.9 \%$ and diagnostic accuracy of $84 \%$ even at 30 week interval. Uterine artery PI was found to be $76.9 \%$ sensitive, $82.9 \%$ specific and had 79\% diagnostic accuracy at 30 weeks.

Umbilical artery RI was found to be $80 \%$ sensitive, $74.3 \%$ specific and had a diagnostic accuracy of $78 \%$ at 30 weeks whereas Umbilical artery SD ratio was $70.8 \%$ sensitive and $65.7 \%$ specific and had a diagnostic accuracy of $69 \%$ at 33 weeks interval.

MCA RI had only $60 \%$ sensitivity and $71.4 \%$ specificity at 36 weeks interval whereas MCA PI had $66.2 \%$ sensitivity and $68.6 \%$ specificity at 36 weeks interval. MCA PSV was not found to be a useful tool as it did not produce a significant difference between two groups.

\section{DISCUSSION}

In the present study, statistically significant difference in mean umbilical artery RI of two groups at all time intervals was observed. A very weak to almost negligible inverse correlation between RI and time was observed in both the groups. The 30 week RI $>0.68$ showed to be $80.0 \%$ sensitive, $74.3 \%$ specific with a positive predictive value of $85.2 \%$ and a negative predictive value of $66.7 \%$. Overall diagnostic efficacy of the test was found to be $78 \%$. North et $\mathrm{al}^{4}$ reported a sensitivity of $47 \%$ and specificity of $91 \%$ for prediction of FGR. In present study, a relatively higher diagnostic efficacy was achieved, though the specificity was lower as compared to that of North yet the sensitivity was quite high. In the study of Kurmanavicius et $\mathrm{al}^{5}$ the $95 \%$ percentile value of RI for umbilical artery resistive index at 30 weeks was found to be around 0.9 .

Statistically significant difference in umbilical artery SD ratio of two groups was seen at all time intervals. A very weak to almost negligible inverse correlation between $\mathrm{SD}$ ratio and time was observed in both the groups. The higher sensitivity of the present study against lower specificity could be because we have taken a relatively relaxed criteria for inclusion, thereby increasing the sensitivity while compromising the specificity to some extent.
The 33 weeks SD ratio $>3.13$ showed to be $70.8 \%$ sensitive, $65.7 \%$ specific with a positive predictive value of $79.3 \%$ and a negative predictive value of $54.8 \%$. Overall diagnostic efficacy of the test was found to be $69 \%$.

The umbilical artery SD ratio was found to be $66.6 \%$ sensitive and $45.4 \%$ specific for adverse perinatal outcome by Lakhkar et al. ${ }^{6}$ The present study reports a better efficacy as compared to that reported by Lakhkar et al. ${ }^{6}$ Byun et $\mathrm{al}^{7}$ reported that poor perinatal outcome was significantly increased in subjects with abnormal umbilical S/D ratio.

Among Color Doppler investigations, mean resistive index in uterine artery amongst non-FGR group was found to be significantly lower as compared to FGR group at all gestational ages. In non-FGR group with the progression of pregnancy, the RI was found to be decreasing. At 30 weeks RI value $>0.535$ was found to be $84.6 \%$ sensitive, $82.9 \%$ specific with a positive predictive value of $90.2 \%$ and a negative predictive value of $74.4 \%$. Overall diagnostic efficacy was assessed to be $84 \%$.

Kurmanavicius et $\mathrm{al}^{5}$ in their study have shown resistive index to be decreasing slightly with increasing gestational age between 30 to 38 weeks of gestation. In present study too, a slight decrease in RI was seen in from 30 to 39 weeks. Our results are in close proximity with the results of Lakhkar et $\mathrm{al}^{6}$ who reported a mean value of 0.49 in normal and 0.65 in abnormal pregnancy group at 28 weeks and 0.45 in normal and 0.64 in abnormal pregnancy at 34 weeks. In present study, at 30 weeks the mean value in non-FGR group was 0.47 and the same in FGR group was 0.63 . The value decreased to 0.42 at 39 week in FGR group but in FGR group it was found to be 0.64 showing a slight increment. Dugoff et $\mathrm{al}^{8}$ in their study showed that women with a high uterine artery mean $\mathrm{RI}$ ( $\geq 75$ th percentile) even at first trimester were 5.5 times more likely to have IUGR as compared to lower uterine artery mean RI. Chung et $\mathrm{al}^{9}$ that a uterine artery RI value $>0.6$ between 26 to 28 weeks' gestation was an evidence of abnormal Doppler velocimetry and had an increased incidence of abnormal pregnancy including FGR.

In a study by Gomez et $\mathrm{al}^{10}$ sequential changes in uterine artery blood flow pattern between the first and second trimesters of gestation in relation to pregnancy outcome were studied. They observed that mean uterine artery PI showed a significant linear decrease within each of the two intervals considered. In present study too, in the non-FGR group, a linear decrease in PI was seen $(r=-0.408)$. They showed that compared with pregnancies with a normal outcome, complicated pregnancies showed a significantly higher mean PI in each of the two intervals studied. In present study too, at each time interval the mean PI of FGR group was found to be significantly higher as compared to that of non FGR group $(\mathrm{p}<0.001)$. Lakhkar et $\mathrm{al}^{6}$ too have showed a significant difference in mean PI of non-FGR and FGR groups. In their study too mean PI in normal pregnancy group showed a continuous decrease from 28 weeks to 38 weeks while in FGR group the mean PI remained almost stable as in our study. Llurba et $\mathrm{al}^{11}$ showed that PI had a sensitivity of $73 \%$ in detection of IUGR. In present study, we found a sensitivity 
of above $76 \%$ for 30 week PI value. Olofsson et $\mathrm{al}^{12}$ in their study too showed that uterine artery PI was significantly more often abnormally high in the pregnancy associated with FGR.

For Middle cerebral artery statistically significant difference in RI of two groups was seen at all time intervals. A very weak to almost negligible inverse correlation between RI and time was observed in both the groups. The 36 weeks $\mathrm{RI}>0.86$ showed to be $60.0 \%$ sensitive, $71.4 \%$ specific with a positive predictive value of $79.6 \%$ and a negative predictive value of $49.0 \%$. Overall diagnostic efficacy of the test was found to be $64 \%$.

The 95th percentile MCA RI at 36 week as obtained by Tarzamni et $\mathrm{al}^{13}$ was obtained to be 0.88 which is too close to the calculated cut-off value in present study. Kurmanavicius et $\mathrm{al}^{5}$ too reported a 95 th percentile value above 0.81 for MCA RI, thereby indicating that all these findings were suggestive of a similar pattern.

Statistically significant difference in PI of two groups was seen at all time intervals except at 30 weeks. A weak negative correlation between time and PI was observed in non-FGR group whereas in FGR group the correlation was almost negligible. It was observed that the differences between two groups were maximum at 39 weeks.

The 36 weeks PI >1.88 showed to be $66.2 \%$ sensitive, $68.6 \%$ specific with a positive predictive value of $79.6 \%$ and a negative predictive value of $52.2 \%$. Overall diagnostic efficacy of the test was found to be $67 \%$.

Tarzamni et al ${ }^{14}$ reported a 90th percentile value of MCA PI at 36 weeks to be 2.20 which is well above the cut-off level in the present study. However, in present study it had a limited success for both resistance index and pulsatility index. It emerged as a late marker for FGR.

Middle cerebral artery PSV did not show a significant difference between two groups, hence it was not explored further. Mari $\mathrm{G}$ et $\mathrm{al}^{15}$ observed that low MCA-PI.MCAPSV might be valuable in clinical assessment of FGR fetuses that have abnormal UA Doppler. Similar views have been expressed by Qahtani et al. ${ }^{16}$

The outcome in terms of mode of delivery revealed a significantly higher incidence of caesarean delivery in FGR group as compared to non-FGR group. The reason for this could be imminent fetal distress. Though the proportion of FGR babies admitted to NICU was significantly higher as compared to non-FGR group, yet no significant difference was observed between two groups in terms of neonatal death. This indicates that with prognosis of FGR and adequate availability of hospital facilities, the FGR babies could be managed perinataly for a better outcome.

However, the utility of Color Doppler findings especially for uterine artery showed a promising efficacy at early gestational age of 30 weeks itself. The utility of MCA findings could not be of much use as they detect only late abnormalities and that too with only a limited precision. Umbilical artery resistive index was also a promising marker at early gestational age.

\section{CONCLUSION}

Doppler measurements for uterine artery showed higher efficacy as compared to umbilical artery and middle cerebral artery findings. The uterine artery RI was found to be $84.6 \%$ sensitive and $82.9 \%$ specific even at 30 weeks. Among different umbilical artery measurements, umbilical artery RI was observed to be the most efficient even at early stage (30 weeks). The findings in this study suggested Color Doppler findings have their significance for finding FGR even at the earliest stage (30 weeks). In present study we observed that the cut-off values obtained by us were in close proximity with the findings in other studies yet a normative database preparation is essential to obtain more precise results.

\section{REFERENCES}

1. Fitzergerald DE,Drumm JE. Noninvasive measurement of fetal circulating using sonography. A new method. Br. Med. J. 1977; 2(1): 1450.

2. Shahinaj R, Manoku N, Kroi E, Tasha I. The value of the middle cerebral to umbilical artery Doppler ratio in the prediction of neonatal outcome in patient with preeclampsia and gestational hypertension. Journal of Prenatal Medicine. 2010;4(2):17-21.

3. Morris RK, Malin G, Robson SC, Kleijnen J, Zamora J, Khan KS. Fetal umbilical artery Doppler to predict compromise of fetal/neonatal wellbeing in a high-risk population: systematic review and bivariate metaanalysis. Ultrasound in Obstetrics and Gynecology. 2011;37(2):135-42.

4. North RA, Ferrier CL long D, Townend K, Kincaidsmith F. Utreine artery Doppler flow velocity waveforms in the second trimester for the prediction of preeclampsia and fetal growth retardation. Obstet Gynecol 1994; 83(4); 378-86.

5. Kurmanavicius J, Florio I, Wisser J. Reference resistive indices of the umbilical fetal middle cerebral and uterine arteries at 24-42 weeks gestation. Ultrasound Obstet. Gynecol. 1997; 10(5): 112-120.

6. Lakhkar BN, Ahamed S. Doppler velocimetry of uterine and umbilical arteries during pregnancy. Indian J Radiol Imaging 1999; 9(3): 119-215.

7. Byun YJ, Kim HS, Yang JI et al. Umbilical Artery Doppler Study as a Predictive Marker of Perinatal Outcome in Preterm Small for Gestational Age Infants. Yonsei Med J 50(1):39 - 44, 2009.

8. Dugoff L, Lynch AM, Cioffi-Ragan D et al. First trimester uterine artery Doppler abnormalities predict subsequent intrauterine growth restriction. Am. J. Obs. Gyn. 2005; 193(3): 1208-1212.

9. Chung JE, Cho JS, Han SS, Parl YW, Kin JW. Uterine artery Doppler Velocimetry in the prediction of adverse obstetric outcomes in unexplained MSAFP elevations. Yonsei Medical Journal 2000; 41(1): 17-21.

10. Gómez O, Figueras F, Martínez JM, del Río M, Palacio M, Eixarch E, Puerto B, Coll O, Cararach V, Vanrell JA. 
Sequential changes in uterine artery blood flow pattern between the first and second trimesters of gestation in relation to pregnancy outcome. Ultrasound Obstet Gynecol. 2006;28(6):802-8.

11. Llurba E, Carreras E, Gratacós E, Juan M, Astor J, Vives A,Hermosilla E, Calero I,Millán P, García-Valdecasas B, Cabero L. Maternal history and uterine artery Doppler in the assessment of risk for development of earlyand late-onset preeclampsia and intrauterine growth restriction. Obstetrics and gynecology international. 2009;2009.

12. Olofsson P, Laurin RN, Marsal K. A high uterine artery pulsatility index reflects a defective development of placental bed spiral arteries in pregnancies complicated by hypertension and fetal growth retardation. Eur J Obs. and Gyn. and Reprod. Biology 1993; 49(3): 161-168

13. Tarzamni MK, Nezami N, Sobhani N, Eshraghi N, Tarzamni $M$ and Talebi Y. Nomograms of Iranian fetal middle cerebral artery Doppler waveforms and uniformity of their pattern with other populations' nomograms. BMC Pregnancy and Childbirth 2008, 8:50

14. Tarzamni MK, Nezami N, Gatreh-Samani F, Vahedinia $\mathrm{S}$ and Tarzamni M. Doppler Waveform Indices of Fetal Middle Cerebral Artery in Normal 20 to 40 Weeks Pregnancies. Arch Iranian Med 2009; 12 (1): 29 - 34.

15. Mari G, Hanif F, Kruger M: Middle Cerebral artery peak systolic velocity: a new Doppler parameter in assessment of growth- restricted fetuses. 2007; 29 (3): 310-6.

16. Qahtani NA. Doppler Ultrasound In The Assessment Of Suspected Intra-uterine Growth Restriction. WebmedCentral Obstetrics and Gynaecology 2010;1(10):WMC001068.

Source of Support: Nil; Conflict of Interest: None

Submitted: 10-03-2018; Accepted: 12-04-2018; Published online: 05-05-2018 